\title{
The Effect of Discipline-Related Knowledge on Heritage Language Learners' Reading Comprehension
}

\author{
By Edna Velásquez
}

This study explores the effect of prior discipline-related knowledge in reading comprehension for two groups of students of Spanish as a Heritage Language (SHL). The first group (G1), had 22 students enrolled in a general Spanish course and the second (G2), had 18 students enrolled in a course of Spanish for medical professions. The aim was to determine whether G2's reading comprehension of a text related to medicine was better than G1's. The instruments used were a lexical recognition test (LR) and a reading comprehension questionnaire (RC), both based on an article related to medicine. The former was used to verify the lexical baseline for both of these groups. From the results of the latter, we conclude that having prior thematic knowledge (in the area of medicine) had no effect on the understanding of this text. Additionally, at lower levels of lexical recognition (between 50\% and 70\%), the contribution of prior knowledge seemed to be greater, which could indicate that these students would greatly benefit from pre-reading activities that might activate previous knowledge or familiarize them with the topic.

Keywords: Discipline-related knowledge, reading comprehension, Spanish, Heritage language, lexical recognition.

\section{Introduction}

In many contexts, reading is arguably the most important of the four communicative skills. Carrell (1988) points out that it is essential in second and foreign language learning settings. It is also essential for learning languages for academic purposes - i.e, for those enrolled in courses where abundant reading material is used in the target language. It is clear that if these students want to be able to compete with native speakers and advance academically and professionally, they need to develop good reading skills.

Grabe (1991) also recognizes that reading is perhaps the most important skill for students of second languages in academic contexts, which has contributed to an increase in the number of studies in this area in recent years. Particularly, given the lingua franca status of English, most studies have been conducted for English as a Second Language (ESL), as a Foreign Language (EFL) and for English for Academic Purposes (EAP), as will be seen later in the discussion of previous studies. However, given the current internationalization of markets, an increasingly

${ }^{*}$ Clinical Assistant Professor, University of Houston, USA. 
globalized economy, and migratory flows, other languages are beginning to gain importance on the world stage. This is the case of Spanish, whose presence and importance in the United States are reflected at the governmental level, in the media, business and education (Beaudrie \& Fairclough, 2012).

According to the 2010 census, the Hispanic population in the United States surpassed 50 million (constituting 16\% of the total population) and it is projected that by the year 2060, it will be around $32 \%$ of the total population (US Census Bureau, 2010). Spanish is the second most spoken language in the United States with more than 700,000 students (more than half of the total foreign language enrollment) taking Spanish classes in higher institutions (MLA survey, fall 2016). This greater presence of Spanish explains the growing demand for university courses in Spanish as a foreign language (SFL) and as a heritage language (SHL).

Valdés (2001) identifies a Heritage Language Learner (HLL) as "an individual who is raised in a home where a non-English language is spoken, who speaks or at least understands the language, and who is to some degree bilingual in that language an in English" (p. 38). The author also points out these students are different from the traditional foreign language students in important ways and that this difference has to do with developed functional proficiencies. From this widely accepted definition it is easy to infer that HLLs' linguistic and pedagogical needs are different from those of foreign language students.

Campbell and Rosenthal (2000) state that HLLs come to the classroom with certain superior language skills, which students of foreign language classes could only access after many years of formal study. However, since most of HLLs have not received formal instruction in Spanish, they have had limited access to the prestigious variety of the language and therefore their linguistic uses are characteristic of rural or informal varieties learned at home or in the community.

According to Chevalier (2004), a common characteristic among Heritage Learners across languages is a "lack of familiarity with the full range of stylistic registers available to the educated native speaker" (p. 27). An educated speaker possesses a wide repertoire of formal discourse, including formal speech registers and written genres, to achieve different communication goals. Heritage Learners' linguistic repertoire, on the contrary, is very limited due to their restricted participation in communicative situations, or linguistic domains. They ultimately limit the use of their Heritage Language to the home and family domain characterized by "a casual, conversational speech style, used with familiar interlocutors to a restricted set of topics focused on everyday life" (Chevalier, 2004, p. 28).

Several authors (Chevalier, 2004; Colombi \& Harrington, 2012; Colombi \& Magaña, 2013) advocate for the development of an advanced 'biliteracy' for HLLs in the university setting that would enable them to alternate between their vernacular variety, the standard variety and academic registers. In this way, they could change their register according to the demands of the social context. Regarding the acquisition of the academic variety of Spanish, Colombi \& Magaña (2013) argue that: "The development of academic Spanish increases linguistic repertoires in academic and professional contexts, thereby offering more job and professional opportunities." (p. 341) 
In terms of employment opportunities, there is statistical evidence showing a high demand for bilingual Hispanic professionals in the United States in areas such as business, commerce and medicine, among others. In medicine, the need for translators and interpreters, and bilingual medical assistants or nurses stands out. Therefore, the researchers assert, the demand for courses in Spanish for specific purposes (business, legal, medical, etc.) at the University level is not surprising.

Colombi and Magaña (2013) cite some examples of universities where courses are already offered to address the need for bilingual professionals in the United States. They mention an innovative program recently implemented for Spanish speakers at the University of Texas Pan American (UTPA) that offers a specialization in medical Spanish. Martínez (2010) describes this medical Spanish program as focused mainly on the development of linguistic skills through content related to the medical professions. He states:

Finally, SHL has recently been viewed as a resource for the professions that are progressively becoming more globally competitive. Workforce development in the United States, it is argued, must adjust to the international competition that has been spawned by globalization. (Martínez, 2012, p.70)

Beaudrie (2012) recognizes the progress in recent years in the creation of university programs designed to meet the needs of Spanish speakers in the United States. However, she points out that more qualitative and quantitative research is needed to identify effective pedagogical practices, curricula and programs to ensure that HLLs benefit from high quality instruction.

The experts seem to agree that the most important areas that these students need to develop to achieve access to the prestigious variety of Spanish are reading, writing and vocabulary acquisition (Schwartz, 2003; Valdés, 1997). However, studies in these areas are scarce. For this reason, the objective of this article is to report the results of a preliminary descriptive study with HLLs about the contribution of one of the factors that has traditionally been considered as influential in reading comprehension: previous knowledge of the discipline.

The research question we sought to answer in the present study was: Does previous Medicine-related Knowledge have a positive effect on the comprehension of a text related to medicine for Heritage Language Learners of Spanish? In order to answer it, we compared two groups of HLLs. The first group (G1), had 22 students enrolled in a general Spanish course and the second (G2), had 18 students enrolled in a course of Spanish for medical professions. The aim was to determine whether G2 would score higher than G1 in a reading comprehension test of a medicine-related text.

The following section will delve into some previous studies about SHL reading and some findings about the effect of discipline-related knowledge on ESL, EFL and EAP reading. 


\section{Literature Review}

\section{Studies on HLL Reading}

To begin with, Faltis (1984) studies the relationship between students and instructors' perceptions regarding reading and writing in Spanish and the reading tasks in textbooks and the ones assigned by the instructors. They conclude that although students report a greater practice of informal -non-academic- reading and writing, most of the reading activities ( $82 \%$ ) assigned by the language instructors are on academic subjects. The study also concludes that instructors give greater importance to reading than to writing. Besides, although instructors reported to highly value non-academic literacy, assignments in their courses were mostly of academic nature.

In another study, Rodrigo, McQuillan, and Krashen, (1996), conclude that free reading has a positive effect on the acquisition of academic vocabulary for HLLs. Samaniego and Pino (2000) also argue that reading is essential to increase vocabulary and to improve other skills such as writing, grammar knowledge, the development of critical thinking strategies and to expand HLLs knowledge in general. These authors emphasize the importance of explicitly teaching different reading strategies, such as prediction, scanning and skimming, etc. They argue that although students use these strategies while reading in English, it is not clear that they are transferring them to Spanish: "Even when these students have already mastered these skills in English, they need to be made aware that the same skills can be used in Spanish" (pp. 40-41).

Hislope (2003) touches on one of the most studied factors said to affect reading comprehension, prior thematic knowledge. This descriptive study with 10 HLLs aimed to explore their reading habits and skills. The participants read a 4page article with abundant use of present subjunctive constructions. Then, they answered some questions that measured their recognition of present subjunctive forms. Contrary to the expectations, the excess of subjunctive forms in reading does not positively affect the ability of these readers to recognize it later in the questions. The author concludes that instruction focused on form needs to be more explicit. In addition, given the low performance in terms of reading comprehension found in this group of students, he concludes that it is necessary to activate prior thematic knowledge before reading, even with articles about familiar topics. In this regard, he points out:

The reading was simple, and they did not perform well. The topic of the article relates to family values. They all have background knowledge on that topic. If we give our students a completely unfamiliar topic without supporting exercises to activate background knowledge we can only imagine the dire outcome. (p.14)

In another study about SHL reading, Velásquez (2016) investigated the relationship between lexical competence and reading comprehension for HLL college students and the lexical coverage needed to show adequate comprehension of an authentic text. On one hand, she validated the vocabulary knowledge percentage of 98\% found for ESL reading by Schmitt, Jiang, \& Grabe (2011), but on the other, she found a different type of function to describe the relationship 
between lexical coverage and reading comprehension. Her study concluded the curve that best described the relationship between these two variables was not linear (as in Schmitt et al for ESL), but obeyed to the law of diminishing returns, better represented by a logarithmic function. This means, beyond certain lexical coverage range, reading comprehension started to diminish which corroborates Davies (2005) findings for Spanish as a Second language reading.

These few studies found are a clear sign that despite the importance attributed to reading, there is still a gap in the research. Particularly, the effect of prior discipline-related knowledge in SHL reading comprehension is an aspect that needs to be studied and that can shed light on how we can help these students to improve their reading comprehension.

In the following section, we will discuss some results of recent studies on the effect of prior knowledge of the discipline in reading comprehension for ESL, EFL and EAP (fields where most of the research has been conducted). We will then describe our pilot study and discuss the results obtained.

\section{Studies on Discipline-Related Knowledge and Reading Comprehension}

In order to improve reading comprehension, specialists have focused on the study of the possible factors that might influence this skill. Some studies are on the influence of the reader's gender and interest (Brantmeier, 2001; 2003; 2006; Bügel \& Buunk, 1996); their linguistic ability (Clarke, 1979; Cziko, 1980); Vocabulary knowledge (Hu \& Nation, 2000; Laufer, 1989; 1996; Nation, 2006; Schmitt, Jiang, \& Grabe, 2011) and other studies consider prior knowledge as an important factor. The latter sometimes allude to cultural knowledge (Schreck, 1981; Pickens, 1982), other times to the thematic knowledge or familiarity with the subject (Recht \& Leslie, 1988) or sometimes to prior knowledge of the discipline or specialized academic knowledge (Alderson \& Urquhart, 1988; Chen \& Donin, 1997; Peretz \& Shoham, 1990; Usó-Juan, 2006). It is to this last type of knowledge that we will be referring to in this work.

Empirical studies on the effect of discipline-related knowledge on reading comprehension have yielded contradictory results (Lahuerta, 2009). On one hand, there are those that assign a positive effect to the knowledge of the discipline in reading comprehension (Alderson \& Urquhart, 1988; Usó-Juan, 2006) and on the other hand, those that conclude that students do not always demonstrate a better understanding of the texts belonging to their study disciplines (Peretz \& Shoham, 1990; Koh, 1984).

Alderson and Urquhart (1988) report the results of two studies that sought to test the hypothesis that the study discipline to which the EFL students belong has an impact on their reading comprehension. The participants in both investigations, from various academic disciplines (administration, engineering, mathematics, physics and human sciences), had a similar linguistic competence according to the scores obtained in a placement test. They answered five reading comprehension tests after reading five passages from different disciplines.

The results indicate that the performance of the students in the comprehension test was much better when the text dealt with subjects related to their own study 
disciplines. These authors concluded that: "Below a certain level of text difficulty (of necessity undefined), a certain score could be arrived at by means of (a) linguistic proficiency and (b) general knowledge of the world." (p.181). And also, "Beyond a certain level of linguistic difficulty, more specialized background knowledge would become more important, being used to 'top up' linguistic proficiency scores." (p. 181)

This confirms the hypothesis of the positive effect of prior knowledge in reading comprehension. In addition, the authors conclude that students in specific areas may be at a disadvantage when their reading comprehension is evaluated in subjects that are not part of their study discipline.

One more study on the contribution of prior knowledge and the level of English proficiency in reading comprehension is that of Usó-Juan (2006). The researcher examines whether the low performance in any of these variables (prior knowledge and linguistic ability) can be compensated with a better performance in the other variable, in the case of EAP reading. The participants in this study were 380 native speakers of Spanish enrolled in three different Colleges (Humanities and Social Sciences, Economics and Law and the College of Technology and Experimental Sciences) at the Jaume I University in Castellón, Spain. These students took three types of tests: a reading comprehension test of a text related to their discipline, a general linguistic ability test and a test to measure their previous knowledge of the discipline.

After submitting the results to statistical and multiple regressions analyses, the author concluded that the contribution of the previous knowledge variable accounted for a range of variation between $21 \%$ and $31 \%$ of the reading of academic texts. The linguistic ability or English proficiency accounted for a range of variation between $58 \%$ and $68 \%$ of reading for academic purposes. The author concluded that if the student's linguistic competence is advanced or intermediate, they could obtain a satisfactory understanding without having prior knowledge of the subject. On the contrary, students with low levels of linguistic competence would need to reach a certain linguistic threshold and also have prior knowledge to be successful readers.

The results of Peretz and Shoham (1990) are somewhat contrary to those of the two previous studies. That is, they concluded that prior knowledge does not necessarily affect reading comprehension in a positive way. The participants, 177 EFL students in an Israeli university, 80 of Science and Technology and 97 of Humanities and Social Sciences, read two academic texts, one in each of these specialties. The texts were not highly specialized, and were deemed appropriate for first-year university students. They found that the more general the text, the better the students' understanding. Science students performed well in both familiar and non-familiar texts.

Peretz and Shoham also concluded that there is no correlation between the perception of the difficulty of the text and the results of the reading comprehension test. Students intuitively prefer texts related to their discipline of study as they consider them easier to read, but the reading comprehension tests results do not reflect their expectations.

Fernández Toledo (2003) explains the differences between the results 
obtained by Alderson and Urquhart (1988) and Peretz and Shoham (1990). He states that:

This may be due to the different degree of specialization of the subjects, which coincides with Zuck and Zuck (1984)'s theory on an effect of the degree of specialization on the type of processing. Apparently, at lower levels of specialization, not only recent knowledge of the subject, but also other general prior knowledge acquired previously, can be intermingled to influence reading comprehension. In another study by Bernhardt (1991), prior knowledge of the subject even negatively affects reading comprehension in the case of some subjects and at different levels. In any situation, it seems that it is difficult to determine the degree of influence of prior thematic knowledge as an isolated element in low levels of thematic specialization. (p.107)

From the studies discussed so far, it is easy to deduce that determining the influence of prior knowledge of the discipline on reading comprehension is not an easy task as there are other variables involved such as the degree of difficulty of the text and the degree of specialization of the readers, among others.

Other type of studies aims to see the interaction between the previous knowledge and the linguistic ability of the reader. They are based on Clarke's Lexicon Threshold Hypothesis (1979), known at the beginning as the Short Circuit Hypothesis. According to this theory, students must achieve a certain level of control in their second language (L2) or they must reach a linguistic threshold to be able to transfer reading strategies in their native language to reading in a second language. Readers located below the threshold, or what Clarke called "ceiling" would not be able to transfer their reading skills. A short circuit would occur that would not let them use the proper reading strategies if the reading task in L2 is too complicated.

One of the studies based on this hypothesis is that of Hammadou (1991), who sought to check whether prior thematic knowledge led to a better inferential ability and whether this depended on the level of linguistic ability in the foreign language. He found that there was no direct relationship between prior thematic knowledge and better understanding. Apparently, the most familiar text was the one least remembered by the participants, which leads to the conclusion that thematic familiarity does not have a compensatory effect on low levels of linguistic ability.

Hudson (1982) demonstrates that the activation of prior knowledge as part of pre-reading activities can counteract the deficiency of language skills. The greatest effect is observed with beginner and intermediate level ESL students. This result contradicts that of Koh (1984) according to which readers of L2 understand better the texts of familiar subjects, independently of their linguistic ability.

Lahuerta (2009) points out that, although contradictory results have been found regarding the effects of prior knowledge and the reader's linguistic ability in reading comprehension, recent findings suggest "successful EAP reading comprehension depends on a great extent on the discipline-related knowledge and English-language proficiency." (p.49). This author also discusses some research that indicates the existence of a compensatory effect between these two variables: "There is also a strong compensatory effect between these variables for successful EAP reading and students with low-level English proficiency can successfully 
read academic passages if they have reached a linguistic threshold and have discipline-related knowledge." (p.50)

All these studies show the relevance of teaching languages for the professions and offer an insight on how results can help to chart paths for better curriculums, evaluation practices and textbook design for these classes. However, as mentioned earlier, in the case of SHL, the research is almost non-existent and it is a field that needs to be explored especially in view of the recent incursion of Spanish for the professions programs in some universities in the United States. It is necessary for these programs to take advantage of the linguistic resources offered by their HLLs.

\section{Methodology}

To explore the effect of prior knowledge of the discipline on SHL reading comprehension, a descriptive study was conducted with two groups of HLLs that were classified as intermediate level at two different Higher Education institutions in Texas. One of the groups was studying general Spanish in a traditional course specifically designed for HLLs, without any emphasis on any particular discipline. The other was a group of students of Spanish for the medical professions. The aim was to compare the reading comprehension performance of these two groups after taking a reading comprehension test of a text related to medicine.

The research question we sought to answer in the present study was: Does previous Medicine-related Knowledge have a positive effect on the comprehension of a text related to medicine for Heritage Language Learners of Spanish?

Detailed information on the participants and the instruments used will be offered in the next sections.

\section{Participants}

The first of the two groups participating in this study (G1) had 22 students enrolled in an intermediate course for HLLs at a Metropolitan University in Texas. All students at this institution are expected to complete 6 credit hours at the intermediate level to fulfill the foreign language requirement. There are two language-learning programs: Second Language and Heritage Language. The Second Language Program is designed for students who learned Spanish formally while in school and those students with no previous Spanish language knowledge or background. The Heritage Language Program is for students who grew up in an environment where Spanish was spoken. They may be fluent in Spanish or just understand it. Both programs offer several undergraduate level courses in Elementary, Intermediate and Advanced Spanish, designed to develop all four language skills: listening, speaking, reading and writing, as well as culture. Placement in the correct course is based on specific placement exams. The course sequence (at the time of the present study) in the SHL program was as follows:

First-year Spanish for HL (one course): Intensive Elementary Spanish Second-year Spanish for HL (two courses): Spanish for HL 1 and Spanish for HL 2. 
G1 participants were enrolled in a Spanish for HL 1 course and they were majoring in Communication, Journalism, Engineering, Psychology, Anthropology and Political Science.

The second group of participants (G2) consisted of 18 HLLs enrolled in a Medical Spanish course at another Texan Higher Education Institution. This is the first of four intermediate and advanced courses that constitute the Medical Spanish for Heritage Learners (MSHL) academic minor. As in the case of G1, students in this group were also at the intermediate level. However, unlike G1, these students were all majoring in areas related to medicine and health sciences, such as nursing, occupational therapy, pharmacy, medical care, rehabilitation and clinical laboratory.

The courses in this program focus on the context-based development of targeted language skills for healthcare professionals and on gaining critical awareness of the effects of multilingualism on population health (Martinez, 2010). They are designed to develop three linguistic competences: advanced medical terminology in Spanish, medical interpreting and translation skills, and basic understanding of the public health disciplines. The program combines advanced language and cultural study with multiple service opportunities in the local community and at the national level.

\section{Instruments}

The reading passage utilized for this study was published in a Colombian newspaper and was obtained digitally. The article, entitled: ¿En qué área de la medicina conviene invertir? (Which area of medicine should we invest in?) is an authentic text, written for a broad audience, with some vocabulary related to the medical profession but not very specialized so that an average reader would be able to understand its content.

Participants in each of these groups took two tests, one for lexical recognition (LR) and another for reading comprehension (RC). The latter was a multiplechoice test based on the content of the article they read. No direct questions about vocabulary were included in this test, and all of there were inference type questions. As for the lexical recognition test, its objective was, on one hand, to measure the amount of vocabulary from the passage that each student was able to recognize, and on the other to verify the homogeneity of both groups in terms of their general linguistic competence in Spanish. Numerous studies, some of which are discussed below, establish a high correlation between the students' lexical competence and other linguistic abilities, so it was considered pertinent to measure the students' vocabulary recognition and use this measurement as an indicator of their linguistic ability.

Read (2007), for example, points out the validity of LR tests to measure the amount of lexicon of the students and their linguistic competence. Today, several universities use this kind of tests, mostly along with other additional measures, to place students in different courses by levels or to diagnose their language skills. Fairclough (2011) in a study with speakers of Spanish as a Heritage Language concludes that these types of tests are valid instruments to measure the linguistic 
abilities of this population and proposes its use as placement instrument in the language programs designed for these students.

The lexical recognition test designed for this study contains vocabulary from the reading passage. It consists of 150 lexical items, 100 of which are words taken from the text and 50 are invented words that are not part of the Spanish lexical repertoire, but follow the same morpho-phonological patterns. Some examples of these words are: *hombril, *calorir and *confusing. The students had to mark the words that they recognized as belonging to the Spanish language and to leave unmarked those that did not.

The inclusion of invented words is a control mechanism used in this type of test to discard those students who tend to overvalue their lexical recognition in a language.

The 100 words used in the LR test were chosen from the dictionary of the 5000 most frequent Spanish words by Davies (2006) -A frequency dictionary of Spanish: Core vocabulary for learners. In this dictionary, each word is assigned a number according to its frequency of use and five levels are established. The first level for the thousand most frequent words (with frequencies from 1 to 1000), the second for the following words (with frequencies 1,001 to 2,000), the third for words with frequencies from 2001 to 3,000 and so on up to level 5.

We assumed that the students knew the first level words (articles, pronouns and in general words of low semantic content), so their inclusion was ruled out. We used all words found in the second to the fifth level (69 words in total) and then added 25 words that did not appear in the dictionary because of their low frequency of use. A total of 94 words were obtained. To complete the 100 words we added 6 randomly chosen words from the first level. In this way, a representative sample of the vocabulary of the text was obtained.

\section{Procedure}

Students answered both tests during normal class sessions, with their respective instructors. It took them an average of 40 minutes to answer both the LR test and the RC. The results were collected and scored to start the analysis. The tests were scored using a scale of 0 to 100 , according to the following formula: [(number of correct answers)/(number of questions)] x 100. Then the data was tabulated and we proceeded to analyze the findings.

\section{Results}

Table 1 shows the results of both tests for each group. The average lexical recognition of $\mathrm{G} 1(\mathrm{~N}=22)$ was $85 \%(\mathrm{SD}=7.9)$, very similar to that of $\mathrm{G} 2(\mathrm{~N}=$ 18 ), which was $84 \%$ ( $\mathrm{SD}=10.2$ ). The result of a t test for independent samples, $t$ $(38)=0.12$, $(p=0.89)$, led us to conclude that there was no statistically significant difference between the lexical recognition of these two groups. Because both groups' lexical coverage was homogeneous, we can then infer the comparability of their linguistic skills. 
Table 1. Results of the RC and LR tests for groups G1 and G2

\begin{tabular}{|l|c|c|c|c|}
\hline & Group & $\mathbf{N}$ & Average (\%) & Standard Deviation \\
\hline \multirow{2}{*}{ RC } & G1 & 22 & 48 & 23.0 \\
\cline { 2 - 5 } & G2 & 18 & 51 & 22.7 \\
\hline \multirow{2}{*}{ LR } & G1 & 22 & 85 & 7.9 \\
\cline { 2 - 5 } & G2 & 18 & 84 & 10.2 \\
\hline
\end{tabular}

As for the RC test, the average for $\mathrm{G} 1(\mathrm{~N}=22)$ was $48 \%$, ( $\mathrm{SD}=23.0)$, while for $\mathrm{G} 2(\mathrm{~N}=18)$ it was somewhat higher, $51 \%,(\mathrm{SD}=22.7)$. The result of a t test, $\mathrm{t}$ $(38)=-0.40,(p=0.68)$ revealed that there was no statistically significant difference between the scores obtained in the reading comprehension test of this text related to medicine for these two groups of HLLs.

This would lead us to conclude that the thematic prior knowledge (in the area of medicine) of the G2 group had no effect on the understanding of a text related to this discipline. The G2 group did not demonstrate a significantly higher performance in the reading comprehension test and its comprehension was similar to that of the G1 group without (apparent) knowledge of the discipline.

However, with the help of Figure 1, we can better visualize and analyze the interaction of the variables involved in this study and compare both groups' reading comprehension at different levels of linguistic competence. This figure is the result of grouping LR scores in different ranges (50-55, 55-60, 60-65 and so on) and then averaging the corresponding $\mathrm{RC}$ at those intervals.

Figure 1. Reading Comprehension by Lexical Recognition Ranges

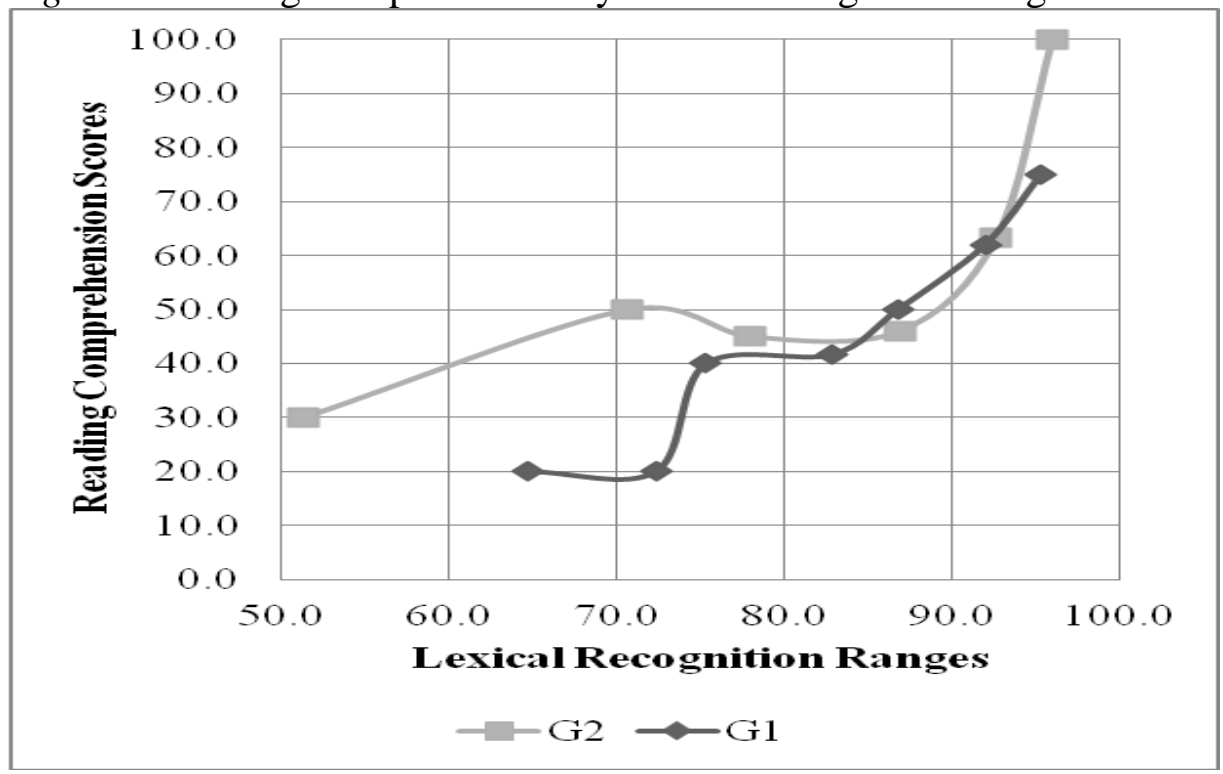

\section{Discussion}

From Figure 1, it is evident that even though the lowest rank of LR was obtained by G2, the reading comprehension of this group was superior in most of the ranges. Between $75 \%$ and $85 \%$ approximately, very similar percentages of 
comprehension were observed for the two groups, but even so, $\mathrm{RC}$ was greater for G2. Between $87 \%$ and $95 \%$, G2's RC is slightly below that of G1, but then in the interval of $95 \%$ to $100 \%$, G2's scores once again surpassed G1's. It should be noted that although $\mathrm{G} 2$ obtained the minimum LR score (51\%), it also obtained the maximum RC score (100\%).

At the lowest levels of lexical recognition (between 50\% and $70 \%$ approximately) is where the greatest difference in reading comprehension could be seen ( $\mathrm{G} 2$ scores were higher than those of G1). It might be that students within that lexical coverage range would benefit more from having prior knowledge of the discipline. Those at higher LR ranges could be using other resources or strategies; therefore other factors would contribute more significantly in their reading comprehension.

In other words, it is at low ranges of lexical recognition (50\%-70\%), where discipline- related knowledge seemed to have an impact on students' reading comprehension. Having previous knowledge of the discipline made a difference and, in a way, seemed to have a compensatory effect for those students with a limited lexical and linguistic competence. Perhaps, at these low LR levels the activation of previous knowledge and explicit vocabulary instruction, as part of the pre-reading activities would greatly help them to improve their reading comprehension.

At first sight our results seem to corroborate some previous studies for ESL (Peretz \& Shoham's, 1990; Koh, 1984), according to which prior disciplinerelated knowledge does not necessarily affect reading comprehension in a positive way. In our case, having prior medicine-related knowledge did not have a positive contribution in HLLs' comprehension of a medical text. This could have been due to the low level of linguistic competence of both groups that is reflected in their low $\mathrm{LR}$ percentages $[\mathrm{LR}(\mathrm{G} 1)=85 \%$ and $\mathrm{LR}(\mathrm{G} 2)=84 \%]$.

Velásquez (2016) concluded HLLs need around $98 \%$ of vocabulary coverage to show adequate comprehension of an authentic Spanish reading passage, which would also help us explain the low RC scores obtained by G1 and G2 (48\% and $51 \%$, respectively). It is evident this reading passage was very challenging for the participants of this study which underscores the importance of choosing appropriate reading materials for this classes.

In conclusion, none of the groups seemed to have reached the linguistic threshold suggested by some scholars (Usó-Juan, 2006; Lahuerta, 2009) and by studies based on Clarke's Lexicon Hypothesis that, in addition to prior knowledge of the discipline, would have made a significant contribution towards an improved reading comprehension.

With such a small sample it is very difficult and risky to draw conclusions regarding the existence of a possible lexical threshold (as suggested in previous studies for EAP, EFL and ESL) that once reached would trigger a stronger effect of discipline-related knowledge on reading comprehension. Nor it is possible from this study alone to draw a conclusion about possible compensatory effects between lexical competence and prior knowledge. For this purpose, it would be necessary to increase the number of participants and possibly refine the instruments for measuring reading comprehension and also prior knowledge. 
Further studies should consider the implementation of additional instruments that allow the measurement of prior knowledge, such as surveys, tests or interviews. Similarly, other complementary reading comprehension instruments, such as 'Cloze' tests or summaries should be used in the future to ensure a more accurate measurement of reading comprehension. Moreover, other studies can be conducted incorporating additional variables that definitely play an important role and that were not considered in this study such as text and test difficulty and the degree of specialization of the students.

Another important factor that should not be ignored is the reader's interest in the topic, which may in some way influence his comprehension. The presence of this and all other variables previously mentioned makes the design of studies like this a very challenging task. However, we hope this can be considered a good starting point in the exploration of the effect of prior knowledge of the discipline in HLL's reading comprehension.

\section{Conclusions}

The present study aimed to compare the reading comprehension performance of two groups of HLLs of Spanish to determine if having prior medicine-related knowledge could have a positive impact reflected in higher scores in a reading comprehension test. Since the difference found in the RC average scores obtained by both groups was not statistically significant, we can conclude that for these two groups, prior knowledge of the discipline did not have a positive effect on the reading comprehension of an authentic newspaper article related to medicine.

One possible explanation we offered is that overall scores were consistent with a low linguistic competence level. Both groups scored very low in the LR test, an indicator of not having enough vocabulary to show adequate comprehension of the reading passage utilized. As previously suggested for ESL and SHL reading, students might need to reach certain linguistic/lexical threshold to be able to take advantage of any prior discipline-related knowledge and this was not the case.

However, a detailed analysis of the reading comprehension figure revealed the medical Spanish group (G2) scored higher in reading comprehension in most of the lexical recognition ranges. This group of students also obtained the minimum LR score (51) and the maximum of RC (100). In the LR ranges below $70 \%$ the difference between the two groups is greater (G2 has better comprehension scores than G1), which seems to suggest that in these ranges prior knowledge's contribution towards reading comprehension is greater.

One of the implications of this finding is that at low LR levels, the activation of previous knowledge and explicit vocabulary instruction, as part of the prereading activities, would greatly help HLLs improve their reading comprehension. We also emphasize the importance of considering other factors that were disregarded in this study and that might have played a major role: text and test difficulty and reader's motivation. In addition, for future studies we suggest the design and implementation of other instruments to measure $\mathrm{RC}$, previous 
knowledge and LR, such as surveys, translations, summaries, interviews, etc.

Extensive academic reading is important for HLLs because it gives them access to the standard variety of the language, by increasing their lexical repertoire. It also provides models that can help them improve their writing skills. Without a strong reading and writing ability, heritage speakers are denied access to the formal register and therefore to many job and academic opportunities, as they cannot compete with native speakers. That is why HLL's instructors should implement effective strategies for explicitly teaching reading through the exploration of the different factors that positively affect this skill.

Studies like this can make an impact on the teaching of Spanish for the professions; a field that is growing and is already showing promising results, especially for Spanish as a heritage language in the United States. Thanks to the needs imposed by the globalization of the labor market, certain minority languages (particularly Spanish), are starting to be considered as potential resources that contribute to the insertion and greater competitiveness in the scenario of the globalized professional market. Today more than ever, researchers and educational administrators are obliged to take advantage of the momentum that these new initiatives are taking to promote more empirical studies that inform pedagogical and evaluation practices thus contributing to validate the importance of these programs.

\section{References}

Alderson, J., \& Urquhart, A.H. (1988). This test is unfair: I'm not an economist. In P. Carrell, J. Devine, D. Eskey, M. Long, \& J. Richards (Eds.), Interactive Approaches to Second Language Reading (pp. 168-182). Cambridge: Cambridge UP.

Beaudrie, S., \& Fairclough, M. (2012). Spanish as a heritage language in the United State: the state of the field. Washington, DC: Georgetown University Press.

Beaudrie, S. (2012). Research on university-based Spanish heritage language programs in the United States: The current state of affairs. In S. Beaudrie \& M. Fairclough (Eds.), Spanish as a heritage language in the United States: State of the field (pp. 203-221). Washington, DC: Georgetown University Press.

Bernhardt, E. (1991). Reading development in a second language. Theoretical, empirical and classroom perspectives. Norwood, NJ: Ablex Publishing Corporation.

Brantmeier, C. (2001). Second language reading research on passage content and gender: Challenges for the intermediate-level curriculum. Foreign Language Annals, 34(4), 325-333.

Brantmeier, C. (2003). Does gender make a difference? Passage content and comprehension in second language reading. Reading in a Foreign Language, 15(1), 127.

Brantmeier, C. (2006). Toward a multicomponent model of interest and L2 reading: Sources of interest, perceived situational interest, and comprehension. Reading in a Foreign Language, 18(2), 89-115.

Bügel, K., \& Buunk, B. P. (1996). Sex differences in foreign language text comprehension: The role of interests and prior knowledge. The Modern Language Journal, 80(1), 15-31. doi: 10.2307/329055.

Campbell, R. N., \& Rosenthal, J. W. (2000). Heritage languages. In J. W. Rosenthal (Ed.), 
(pp. 165-184). Mahwah, NJ: Erlbaum.

Carrell, P. L (1988). Introduction: Interactive approaches to second language reading. In P. Carrell, J. Devine, \& D. Eskey (Eds.), Interactive approaches to second language reading (pp. 1-7). Cambridge, New York: Cambridge University Press.

Chen, Q., \& Donin, J. (1997). Discourse processing of first and second language biology texts: Effects of language proficiency and domain-specific knowledge. Modern Language Journal, 81(2), 209-227.

Chevalier, J.F. (2004). Heritage language literacy: Theory and practice. Heritage Language Journal, 2(1). Retrieved from https://bit.ly/1ckDhsi.

Clarke, M.A. (1979). Reading in Spanish and English: Evidence from adult ESL students. Language Learning: A Journal of Applied Linguistics, 29(1), 121-150.

Colombi, C., \& Harrington, J. (2012). Advanced Biliteracy Development in Spanish as a Heritage Language. In M. Fairclough \& S. Beaudrie (Eds.), Spanish as a heritage language in the United States: The state of the field (pp. 241-258). Washington, DC: Georgetown University Press.

Colombi, C., \& Magaña, J. (2013). Alfabetización avanzada en español en los Estados Unidos en el siglo XX. In D. Dumitrescu, \& G. Piña-Rosales, El Español en los Estados Unidos: E pluribus unum? Enfoques multidisciplinarios (pp. 339-351). New York: Academia Norteamericana de la Lengua Española.

Cziko, G. (1980). Language competence and reading strategies: A comparison of first- and second-language oral reading errors. Language Learning: A Journal of Applied Linguistics, 30(1), 101-116.

Davies, M. (2005). Vocabulary Range and Text Coverage: Insights from the Forthcoming Routledge Frequency Dictionary of Spanish. In D. Eddington (Ed.), Selected Proceedings of the 7th Hispanic Linguistics Symposium (pp. 106-115). Somerville, MA: Cascadilla Proceedings.

Davies, M. (2006). A frequency dictionary of Spanish: Core vocabulary for learners. New York: Routledge.

Fairclough, M. (2011). Testing the lexical recognition task with Spanish/English bilinguals in the United States. Language Testing, 28(2), 273-297. doi:10.1177/026553221039 3151.

Faltis, C. J. (1984). Reading and writing in Spanish for bilingual college students: What's taught at school and what's used in the community. Bilingual Review / La Revista Bilingüe, 11(1), 21-32.

Fernández Toledo, P. (2003). El conocimiento lingüístico, temático y especializado previos en la comprensión lectora del inglés como lengua extranjera: Estudios sobre el nivel umbral. Ibérica: Revista De La Asociación Europea De Lenguas Para Fines Especificos/Journal of the European Association of Languages for Specific Purposes (AELFE), 5, 101-121.

Grabe, W. (1991). Current Developments in Second Language Reading Research. TESOL Quarterly, 25(3), 375-406. doi:10.2307/3586977.

Hammadou, J. (1991). Interrelationships among prior knowledge, inference, and language proficiency in foreign language reading. Modern Language Journal, 75(1), 27-38.

Hislope, K. (2003). A reading study of Spanish heritage speakers. Reading Matrix: An International Online Journal, 3(2) Recovered from: https://bit.ly/2D9mqs2.

Hu, M., \& Nation, I. S. P. (2000). Vocabulary density and reading comprehension. Reading in a Foreign Language, 23(2), 403-430.

Hudson, T. (1982). The effects of induced schemata on the 'short circuit' in L2 reading: Non-decoding factors in L2 reading performance. In P. L. Carrell, J. Devine, D. E. Eskey, \& M. H. (Eds.), Interactive approaches to second language reading. (pp. 183205). Cambridge: Cambridge UP. 
Koh, M.Y. (1984). The role of prior knowledge in the interpretation of texts. (Unpublished Doctoral Dissertation). University of London.

Lahuerta, M.A. (2009). A state-of-the-art review of background knowledge as one of the major factors that influence reading comprehension performance. Estudios De Lingüística Inglesa Aplicada, 9, 31-57.

Laufer, B. (1989). What Percentage of Text-Lexis Is Essential for Comprehension? In C. Laurén \& M. Nordman (Eds.), Special Language: From Humans Thinking to Thinking Machines (pp. 316-323). Clevedon: Multiling. Matters.

Laufer, B. (1996). The lexical threshold of L2 reading: where it is and how it relates to L1 reading ability. In K. Sajavaara \& C. Fairweather, (Eds.), Approaches to Second Language Acquisition (pp. 55-62). Jyvaskyla: Cross Language Studies.

Martínez, G. (2010). Medical Spanish for Heritage Learners: A Prescription to Improve the Health of Spanish-Speaking Communities. In S. Rivera-Mills \& J. Trujillo (Eds.), Building Communities and Making Connections (pp. 2-15). Newcastle Upon Tyne: Cambridge Scholars Publishing.

Martínez, G. (2012). Policy and Planning Research for Spanish as a Heritage Language. From Language Rights to Linguistic Resource. In M. Fairclough \& S. Beaudrie (Eds.), Spanish as a Heritage Language in the United States: The state of the field (pp. 61-77). Washington, DC: Georgetown University Press.

Modern Language Association (MLA). (n.d.). Enrollments in Languages Other Than English in United States Institutions of Higher Education, Fall 2006 (Full Report). Recovered from https://bit.ly/2dyf3gu.

Nation, I.S.P. (2006). How Large a Vocabulary Is Needed For Reading and Listening? Canadian Modern Language Review/La Revue Canadienne Des Langues Vivantes, 63(1), 59-82. doi:10.1353/cml.2006.0049.

Peretz, A.S., \& Shoham, M. (1990). Testing reading comprehension in LSP. Reading in a foreign language, $7(1), 447-455$.

Pickens, I.R. (1982). A cross-cultural study examining the effects of cultural schemata on the reading comprehension of average sixth grade readers. (Unpublished Doctoral Dissertation), The University of Wisconsin.

Read, J. (2007). Second language vocabulary assessment: Current practices and new directions. International Journal of English Studies, 7(2), 105-125.

Recht, D.R., \& Leslie, L. (1988). Effect of prior knowledge on good and poor readers' memory of text. Journal of Educational Psychology, 80(1), 16-20.

Rodrigo, V., McQuillan, J., \& Krashen, S. (1996). Free voluntary reading and vocabulary knowledge in native speakers of Spanish. Perceptual and Motor Skills, 83(2), 648650 .

Samaniego, F., \& Pino, C. (2000). Frequently Asked Questions about SNS Programs. In AATSP (ed.). Spanish for native speakers, vol. 1. (pp. 29-63). Fort Worth, TX: Harcourt College.

Schmitt, N., Jiang, X., \& Grabe, W. (2011). The Percentage of Words Known in Text and Reading Comprehension. Modern Language Journal, 95(1), 26-43. doi:10.1111/j. 1540-4781.2011.01146.x.

Schreck, J.V. (1981). The effects of content schema on reading comprehension for Hispanic, black, and white cultural groups. (Unpublished Doctoral Dissertation). University of Illinois at Urbana-Champaign.

Schwartz, A.M. (2003). ¡No me suena! heritage spanish speakers' writing strategies. In A. Roca \& M. C. Colombi (Eds.), Mi lengua. Spanish as a heritage language in the United States, (pp. 235-256). Washington, DC: Georgetown UP.

U. S. Census Bureau. (2010). The Hispanic population 2010. Retrieved from https://bit. $1 \mathrm{y} / 1 \mathrm{~mW} 5 \mathrm{fOd}$. 
Usó-Juan, E. (2006). The compensatory nature of discipline-related knowledge and English-language proficiency in reading English for academic purposes. Modern Language Journal, 90(2), 210-227. doi:10.1111/j.1540-4781.2006.00393.x.

Valdés, G. (1997). The teaching of Spanish to bilingual Spanish-speaking students: Outstanding issues and unanswered questions. In M. C. Colombi \& F. Alarcón (Eds.), La enseñanza del español a hispanohablantes: Praxis y teoria (pp. 8-44). Lexington, MA: D.C. Health.

Valdés, G. (2001). Heritage Language students: Profiles and possibilities. In J. K. Peyton, D.A. Ranard \& S. McGinnis (Eds.), Heritage languages in America: Preserving a national resource (pp.37-77). Washington, DC: Center for Applied Linguistics.

Velásquez, E. (2016). Competencia Léxica y Comprensión de Lectura: Un Estudio Piloto con Estudiantes de Español como Lengua de Herencia. Gist: Education and Learning Research Journal, 13, 56-74.

Zuck, L.V., \& Zuck, J.G. (1984). The main idea: Specialist and non-specialist judgements. In Pugh \& Ulijn (Eds.), Reading for professional purposes: Studies and practices in native and foreign languages (pp. 130-135). London: Heinemann. 
